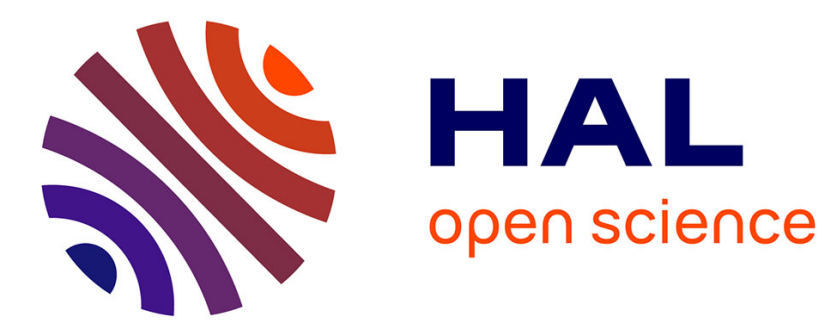

\title{
Pre-consensus Ontologies and Urban Databases
}

Robert Laurini

\section{To cite this version:}

Robert Laurini. Pre-consensus Ontologies and Urban Databases. Towntology workshop, Nov 2006,

Geneva, Switzerland. pp.27-36. hal-01502738

\section{HAL Id: hal-01502738 \\ https://hal.science/hal-01502738}

Submitted on 6 Apr 2017

HAL is a multi-disciplinary open access archive for the deposit and dissemination of scientific research documents, whether they are published or not. The documents may come from teaching and research institutions in France or abroad, or from public or private research centers.
L'archive ouverte pluridisciplinaire HAL, est destinée au dépôt et à la diffusion de documents scientifiques de niveau recherche, publiés ou non, émanant des établissements d'enseignement et de recherche français ou étrangers, des laboratoires publics ou privés. 


\title{
Pre-consensus Ontologies and Urban Databases
}

\author{
Robert Laurini \\ LIRIS - INSA de Lyon, F - 69621 Villeurbanne \\ Robert.Laurini@insa-lyon.fr
}

\begin{abstract}
Facing the difficulties of interoperability and cooperation between several urban databases, a solution is based on ontologies which can help not only clarify the vocabulary used in urban planning, but also organize urban applications; indeed multiple definitions can be given to various urban objects. So this is the scope of the Towntology project which aims at defining ontologies for urban planning whose design is characterized by the multiplicity of definitions. After having presented some ways of using ontologies for various actors in urban applications, a definition of pre-consensus ontologies is given, together with some groupware tools to collect multiple textual and multimedia definitions in sub-ontologies, to check and consolidate the vocabulary in order to reach some consensus. We conclude this paper by giving some recommendations for the Towntology project for covering the whole urban field by integrating various sub-ontologies.
\end{abstract}

Keywords: Urban ontologies, Towntology project, consenus, pre-consensus ontologies, groupware.

\section{1 - Introduction}

One of the main problems we have to face in urban information systems is the problems of interoperability and cooperation between several databases [8]: indeed, each database was created independently from others, i.e. with different entities and attributes with different meanings. Usually, two levels of interoperability are defined, the lower level called syntactic, and the upper level called semantic. As the syntactic level is solved through OpenGIS ${ }^{1}$ recommendations, a general solution of the semantic level is based on ontologies in order to deal with the meaning of vocabulary. But in reality, the vocabulary problem is not only a database problem, but more important is the clarification of the vocabulary used by all actors dealing with urban databases, and especially by urban planners.

For this reason, the Towntology project was launched in 2003 at INSA Lyon in order to create an urban ontology between urban planners and computer scientists (see [7] or [9] for details). Then facing the difficulty to cover the whole urban field, a COST group ${ }^{2}$ was created and placed under the responsibility of Jacques Teller [10]. Now, it regroups more than 15 laboratories in Europe.

The scope of this paper is to give an overview of problems we have to face in order to define urban sub-ontologies and to integrate them into an unique domain ontology.

\footnotetext{
${ }^{1}$ Refer to http://www.opengeospatial.org/standards.

${ }^{2}$ Refer to http://www.towntology.net/.
} 


\section{Robert Laurini}

This paper is organized as follows. In the second section, we will address the necessity of ontogies in urban applications, and second the organization of groupware to create urban ontologies.

\section{2 - Necessity of ontologies for urban applications}

In this section, examples for interoperability in urban applications will be detailed in order to show how ontologies can be used to solve those problems.

\subsection{Examples of interoperability}

The main examples of interoperability in urban databases can be seen in street repairs in which different databases can be used, not only belonging to the municipality (sewerage, traffic light control) but also belonging to different companies such as for water supply, electricity, gas. Other examples can be found in environmental assessment (for instance dealing with pollution control of an international river such as the Rhine or the Danube), and for providing new pervasive services (LocationBased Services).

Let us examine an example in the cooperation of several urban databases, linked to physical hypermedia [2]: find the roadmap for going from the Da Vinci Gioconda painting in the Paris Louvre Museum, to the Velasquez Meninas painting in Madrid Prado Museum. The solution must be found by means of the cooperation of several databases:

- from the Louvre database for exiting from the Gioconda to the next metro station,

- $\quad$ from the Paris Transportation Company to go from the nearest metro station to Paris Airport,

- $\quad$ from the Airlines database to fly from Paris Airport to Madrid Airport,

- from the Madrid Transportation Company for going from the airport to the nearest metro station,

- $\quad$ from Prado database for going from the nearest metro station to the Meninas painting.

\subsection{Definition of ontologies}

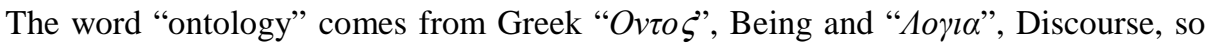
meaning the discourse about existing things. More precisely, ontology refers to the theory of objects and of their relations. Gruber [5] defines an ontology as "an explicit specification of a conceptualization", and Guarino [6] "An ontology is an engineering artifact, constituted by a specific vocabulary used to describe a certain reality, plus a set of explicit assumptions regarding the intended meaning of the vocabulary words". An important aspect is that the various actors must agree about the definition of objects and their relations; so we speak about ontological commitment between actors. 
Pragmatically, a common ontology defines the vocabulary with which queries and assertions are exchanged among actors. Ontological commitments are agreements to use the shared vocabulary in a coherent and consistent manner. From a computing point of view, an ontology can be seen as a semantic network.

But in the case of urban planning, there exist many different definitions of keyobjects such as "city" or "road".

In the Wikipedia ${ }^{3}$, one can find a dozen of definitions of the word "city", but none addresses the whole urban complexity. After Toynbee [11], a city can be defined as a human habitat which cannot provide all food they need, whereas other defines a city as petrified expression of power structures [3]. How to combine those definitions into a single expression?

Let us consider another problem regarding the definitions of "streets". Let us consider three actors in the same city, street cleaners, postmen and gas men: they all can claim "we do have a street file". In reality those files are slightly different:

- street cleaners only clean public streets, so their file only is composed of public streets;

- in theory postmen passes in all streets, but when a cul-de-sac has letter-boxes in a main street, they do not consider those cul-de-sac streets

- for gas men, their file only consists only in streets in which residents have gas.

As a conclusion, even if the concept of street can receive an acceptable definition from urban planners, analyzing several databases can reveal that definitions are different. Generalizing this, we can claim that in practice, even if two databases are using the same word (street), the probability is high that there exist some hidden differences in the definitions.

In other words, multiplicity of definitions is often hidden behind similar terms. To solve this problem, one solution is to define contextual ontologies (See [1] for details.

\subsection{Ontology-based interoperability}

To ensure interoperability, one way is to use ontologies. In the framework, each database is assigned its own local ontology perhaps written from its conceptual model. Moreover a domain ontology is used as a sort of bridge between both local ontologies (i.e. linked to a database) as illustrated in Figure 1. By means of those ontologies, a mediator is generated made in two parts, one for translating the initial query to be accepted by the second database, and the second to transform the results (See Figure 2).

Let us take a small example in demography, with two databases, (i) DB1 with one entity residents, and (ii) DB2 with two entities men and women. How can we get the number of men and women separately in DB1, and the total number of residents in DB2? The second case can be solved by an exact mediator, so giving: DB2 .residents= DB2.men $+\mathrm{DB} 2$. women. However, for the first case, only approximate mediators can be generated, for instance:

$\mathrm{DB} 1 . \mathrm{men}=0.48 \mathrm{XB} 1$. residents

${ }^{3}$ Refer to http://en.wikipedia.org/wiki/City. 
$\mathrm{DB} 1$. women $=0.52 \times \mathrm{DB} 1$. residents.

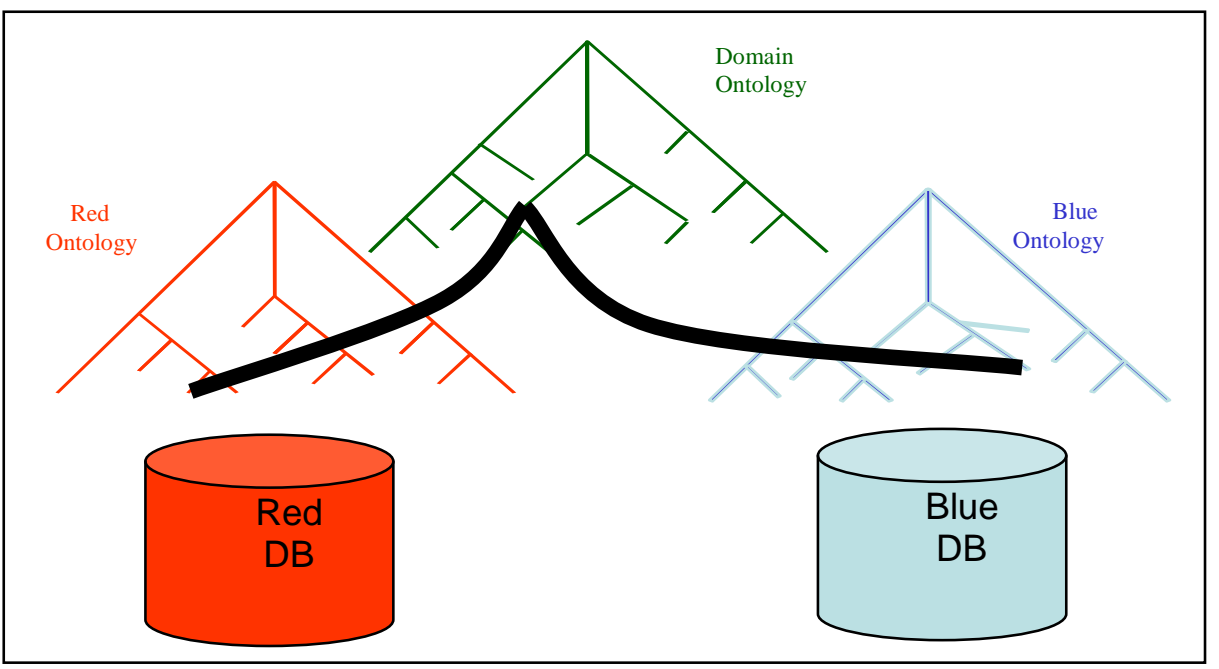

Fig 1. Using domain ontology to ensure interoperability between two databases.

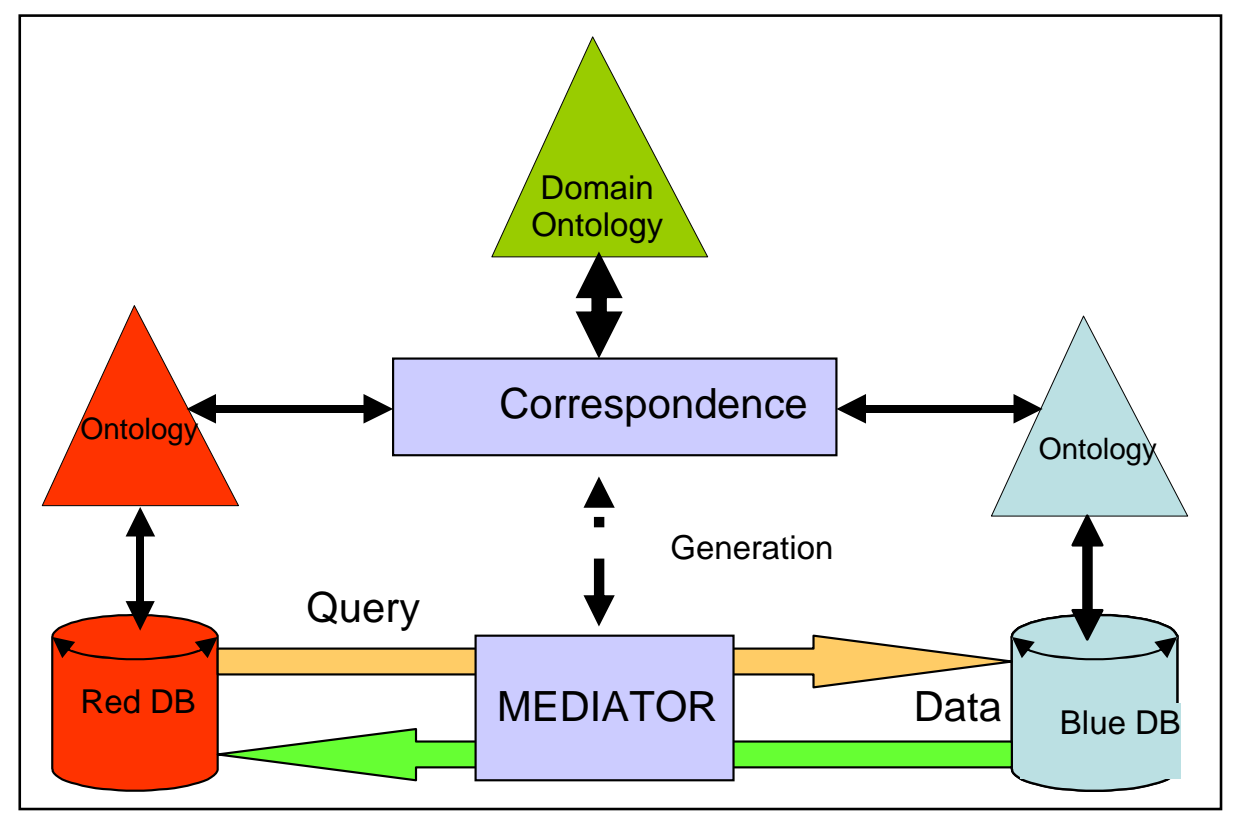

Fig 2. Generation of mediator to ensure interoperability.

The previous formulae can be included into the query-part of the mediators. For the transformation of the results, let us mention an example in distances with different 
units. For instance the data-part of the mediator can transform distances in kilometers by distances in miles.

From a language point of view, ontologies are generally written with languages such as $\mathrm{OWL}^{4}$ which derives from description logics.

\subsection{Specifications of pre-consensus urban ontologies}

Ontologies are easy to define in applications where the vocabulary is well standardized [4]. The topical example is chemistry.

As illustrated in the previous paragraphs, in urban planning, the context is totally different especially due to the variety of definitions. So before translating some textual definition into OWL, some consensus between actors must be found. Now, we can introduce two kinds of ontologies, pre-consensus and post-consensus ontologies as depicted Figure 3. As the majority of existing ontologies can be considered as postconsensus, in our case, our domain ontology in urban planning is a pre-consensus ontology whose main characteristics is the necessity of a repository to collect existing definitions. Then, when all definitions are accumulated, actors can convene to look for a consensus; and when the consensus is reached, translation into OWL can start. It is important not to forget cultural and linguistic problems in this task.

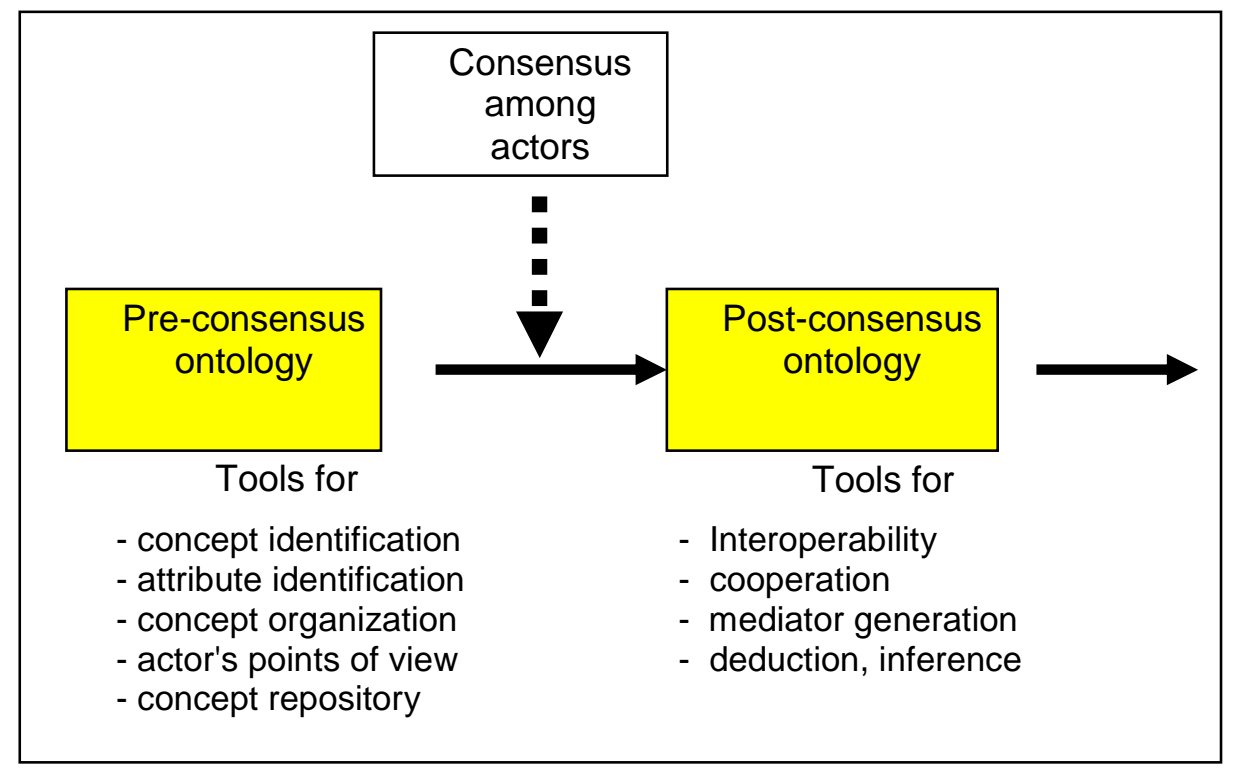

Fig. 3. Differences between pre-consensus ontology, and post-consensus ontology.

So, a repository must be design to collect multiple definitions and attributes. Since in some cases multimedia definitions must be considered, for instance for noise

${ }^{4}$ Refer to http://www.w3.org/TR/owl-features/. 
definitions or in architecture when drawings and sketches are necessary. Another important issue is lineage and traceability of definitions. Finally not only a repository must be defined, but also software tools to manage the various pre-consensus ontologies together with adapted human visual interfaces. Figure 4 illustrates those visual various access methods, (i) from graphs of concepts (semantic network), (ii) from photos illustrating various concepts. In addition to those visual methods, a third one was added based on the alphabetic list of concepts. Since the ontology is represented as a graph, a nice visual solution is to access directly from the graph and to navigate from concepts to concepts. Another interesting access method can be based on photos in which several zones can be activated, especially zones representing concepts; in other words, several photos of cities can be used as entry point into ontologies.

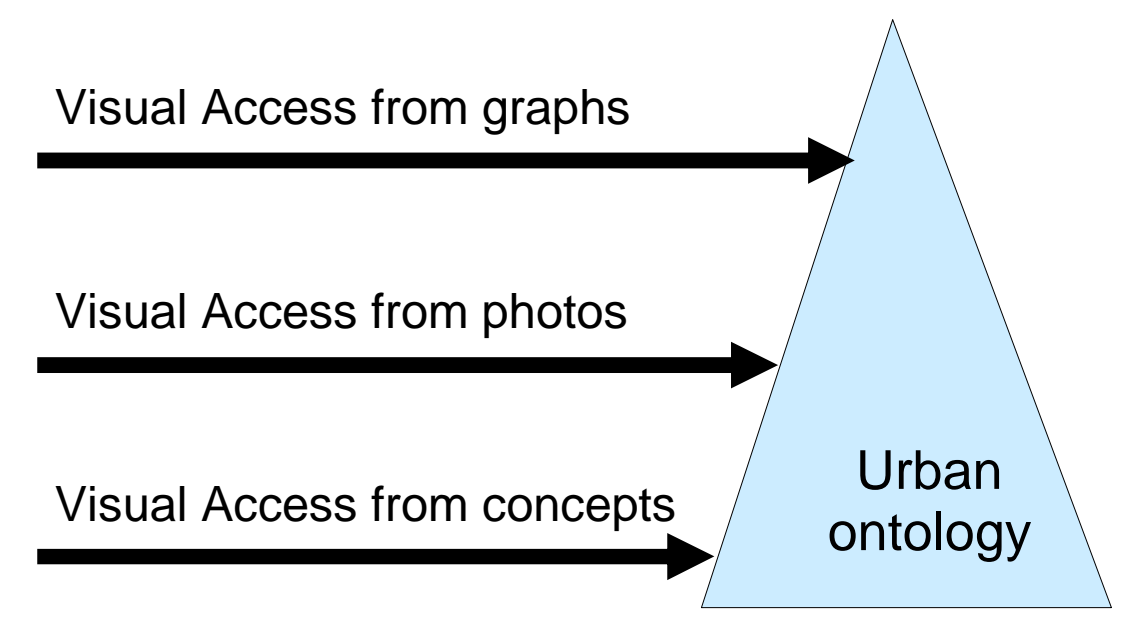

Fig 4. Various ways of accessing to the ontologies.

The access methods based on photos is very important for us because the user is very familiar with urban scenes as given in photos. For integrating a photo into the system, one needs to find rectangular zones corresponding to concepts. Let's take the example of a rectangular zone surrounding a bus. According to the level of abstraction, this zone can correspond to several concepts:

- bus itself,

- bus as a mean of public transportation,

- public transportation,

- transportation of passengers,

- etc.

Finally, the main characteristics of our system are as follows:

- Semantic network,

- Hypertext structure,

- Multiple definitions,

- Origin and lineage of definitions, 
- Possibility of updating,

- Photos and drawings

- Visual presentation.

All main objects of our pre-consensus ontology can be regrouped into a conceptual model given Figure 5.

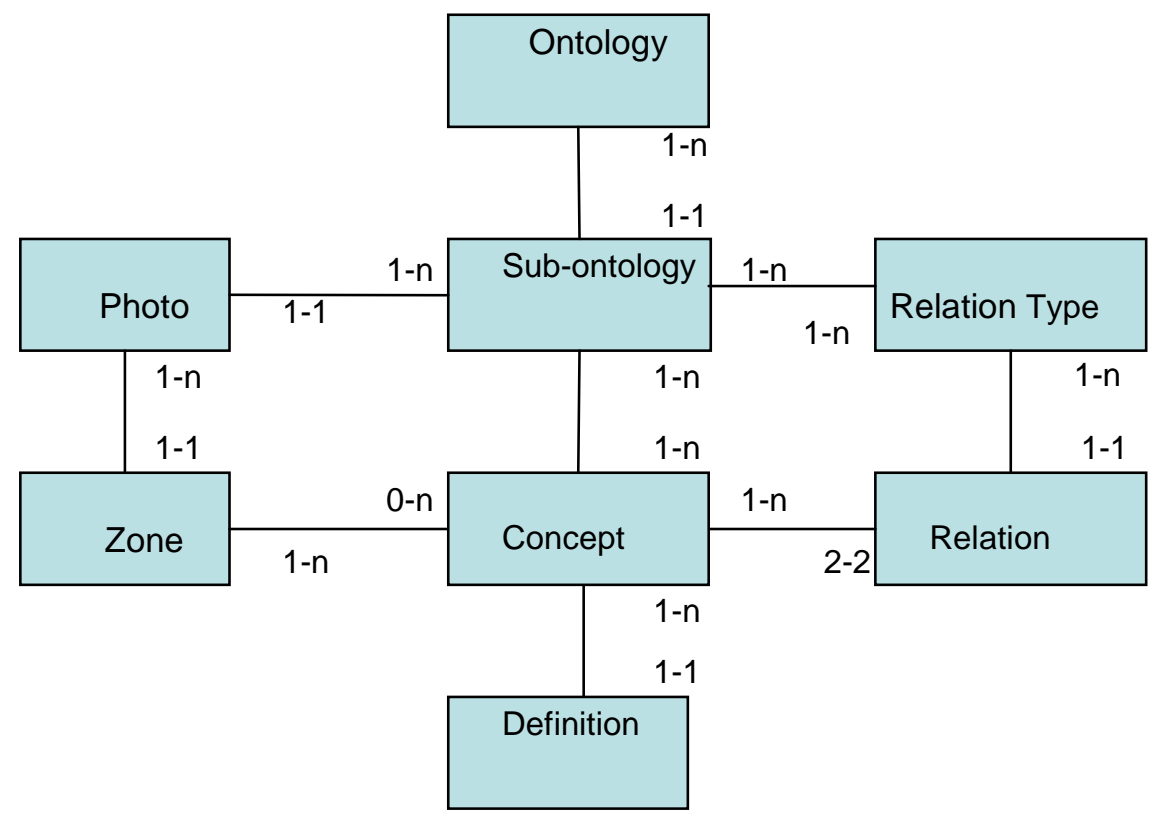

Fig. 5. Conceptual model of a pre-consensus ontology.

\section{3 - Groupware for pre-consensus urban ontologies}

As said earlier, the scope of the Towntology project is to define a complete urban ontology. For that, each laboratory interested is developing its small sub-ontology. The role of the groupware system will be to help those laboratories define preconsensus sub-ontologies, i.e. collect the various multimedia definitions including lineage. For that, each group of actors can work independently on the definition of their important terms. In other words, they need frequently to add some fresh definitions or update them into the repository. When a sub-ontology is ready, it will be presented to the groupware system which will integrate it. Of course a subontology can refer a concept already present in another sub-ontology.

After having very rapidly presented the description language, the groupware system will be sketched. 


\subsection{Language}

Since OWL was not adequate to our problem, taking all those aspects into consideration, a new language was created to store all multimedia definitions into our repository. This language is an extension of XML, some excerpts of the structure of which are given Figure 6. The main divisions are HEAD and BODY. HEAD regroups some identification and metadata regarding this ontology, whereas BODY is really the core of the ontology: the reader can see that any concept can have various multimedia definitions, and every update can be traceable.

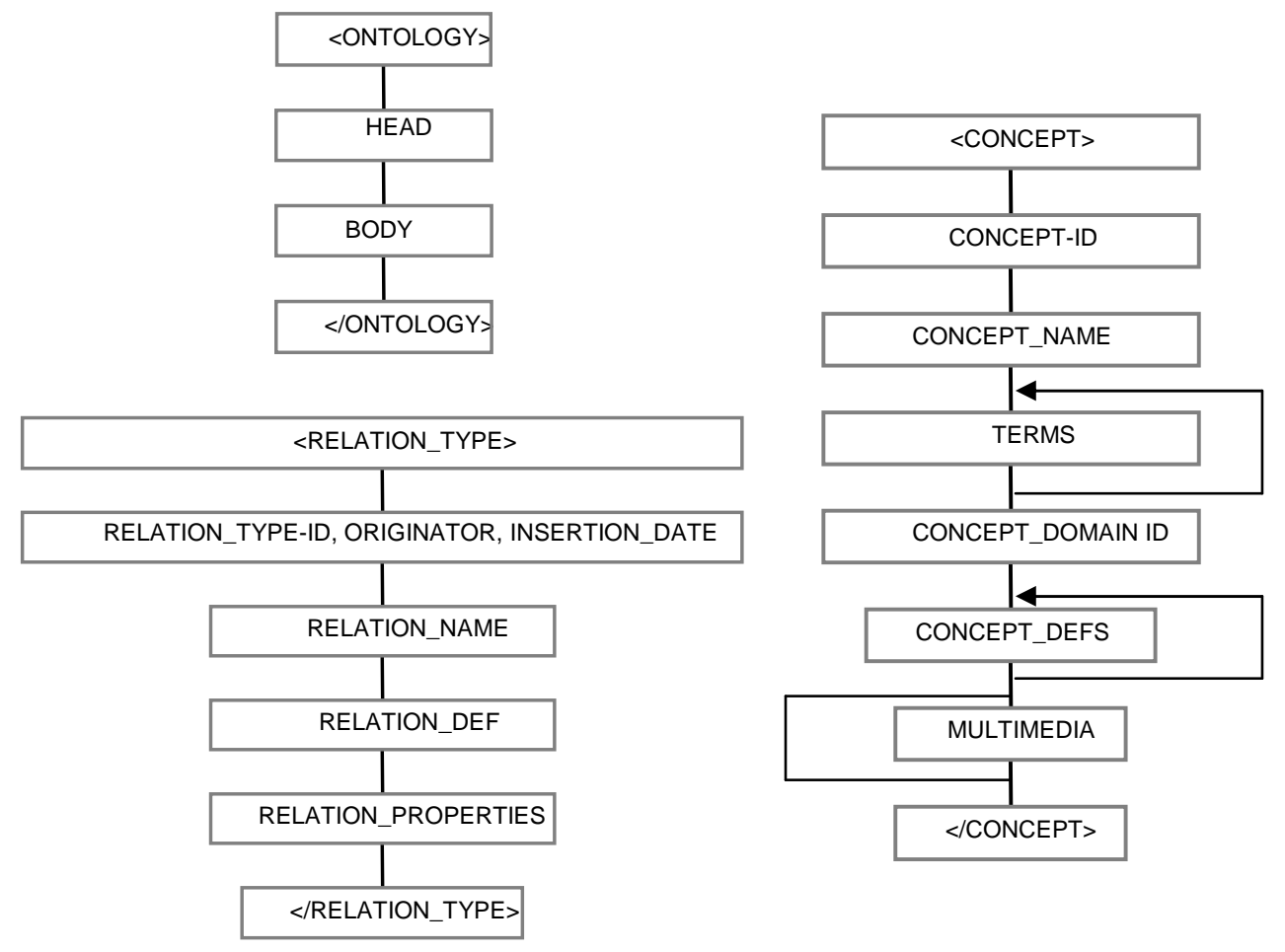

Fig 6. Exerpts of the structure of the Towntology Language.

\subsection{Groupware system}

The groupware system consists of two parts, the first one for creating sub-ontologies, and the second one for integrating sub-ontologies.

For the creating of ontologies, based on the previous language, three modules were written:

- $\quad$ navigating and browsing a sub-ontology, essentially based on the three types of accesses as illustrated Figure 4, 
- $\quad$ updating a sub-ontology, especially by adding new concepts, new definitions and new multimedia resources,

- $\quad$ and preparing an image that can be used as an entry into the sub-ontology; mainly this image is split into rectangular zones which addresses one or several concepts.

The second system is for integrating a new sub-ontology. It consists in several modules:

- $\quad$ validating the proposed sub-ontology, essentially by checking the grammar and some integrity constraints,

- and validating cross-references of concepts with two main aspects: a relation can refer a concept located in another sub-ontology, or a new definition can be added to a concept already stored elsewhere.

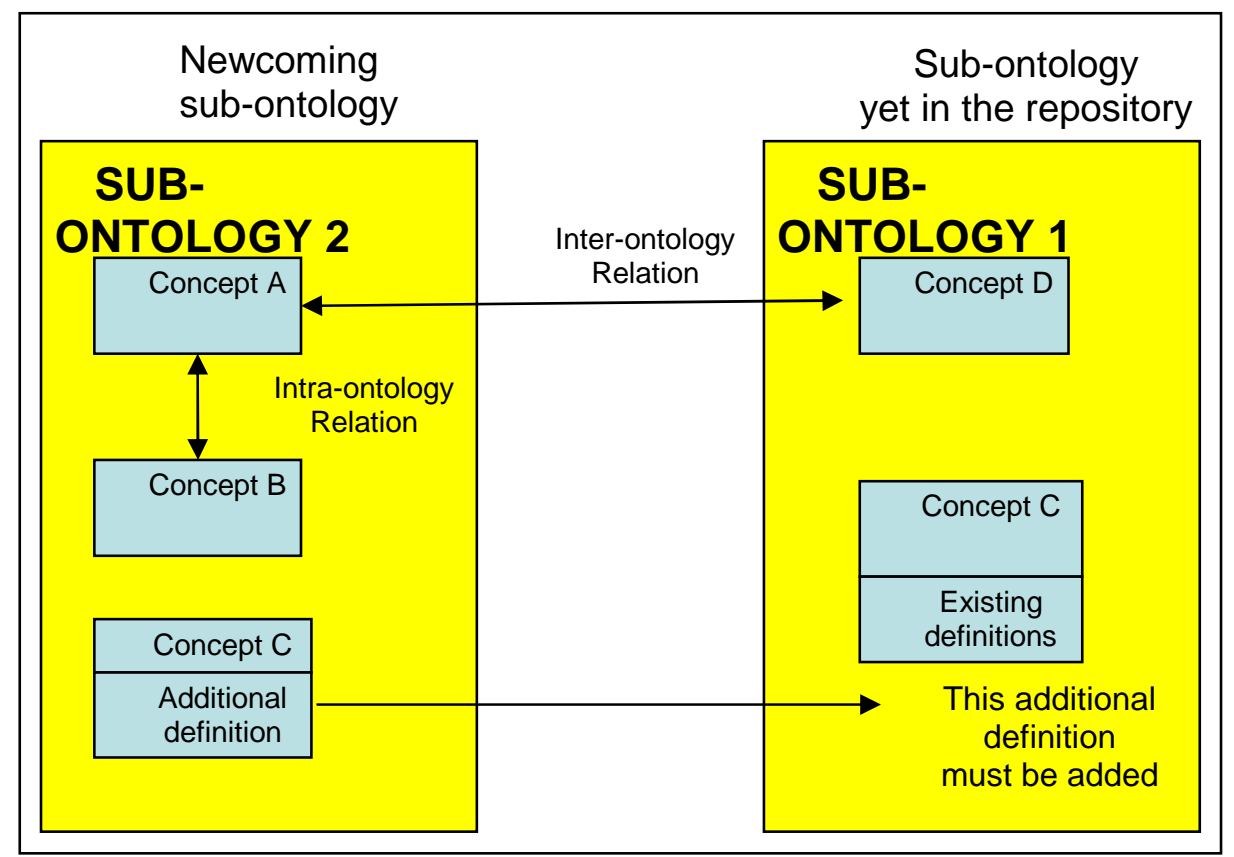

Fig. 7. Integrating a new sub-ontology into the ontology repository.

When all those tasks are made, the new sub-ontology is integrated into the system.

Another module must be written for the seamless browsing of the sub-ontologies. Until now, when a sub-ontology refers to a concept which is located in another ontology, the system only show it; indeed, it could be of interest to continue the browsing without taking those divisions into account.

Several examples of sub-ontologies will be found in this book, together with examples of the navigating system. 


\section{4 - Final remarks}

To conclude this paper, let me remind that the Towntology project was initiated with two scopes, (i) interoperability of urban databases, and (ii) clarification of the vocabulary used by urban planners. Presently, a first software tool exists that can be used to define sub-ontologies. For me the first goal is to populate the various subontologies in order to cover the whole urban field, and for that a first tool was created. When all definitions are collected, the next step is to consolidate those sub-ontologies and check completeness. The subsequent phase will to reach to some consensus; a special tool must be defined, and also a tool for helping the users transform those verbal or multimedia definitions into descriptive logics, so as to code with OWL.

Concerning the language problems, this is not so easy. A naïve way could be to collect terms and definitions in English, and after to translate everything into other languages. One of the first difficulties could be to translate all definitions of very important terms such as cities, towns, urban planning, etc., terms which have sometimes no EXACT counterparts in other languages, especially due to historical, cultural aspects. Similarly a difficulty arises for the translating of legislative terms.

\section{References}

1. Benslimane D., Arara A., Falquet G., Maamar MZ, Thiran P., Gargouri F. (2006). "Contextual Ontologies: Motivations, Challenges, and Solutions". In Proceedings of the Fourth Biennial International Conference on Advances in Information Systems 18-20 October, 2006 Izmir, Turkey. ADVIS 2006 (Springer), 2006.

2. Challiol C., Gordillo S., Rossi G., Laurini R. (2006) "Designing Pervasive Services for Physical Hypermedia". Proceedings of the ICPS'06 : IEEE International Conference on Pervasive Services, 26-29 June 2006, Lyon, France, pp.265-268.

3. French Ministry of Housing (1977) "Programme de Recherche Urbaine du VIIème plan, Paragraphe sur la Poétique des Villes". Ministère de l'Equipement, Paris, 1977.

4. Gómez-Pérez A., Fernández-López M., Corcho O (2004). "Ontological Engineering" Springer Verlag Advanced Information and Knowledge Processing, 2004.

5. Gruber, T.R.(1993) "A Translation Approach to Portable Ontology Specifications". In Knowledge Acquisition, 1993, Vol. 5, № 2, pp. 199-220.

6. Guarino N, (1998) "Formal Ontology and Information Systems", Amended version of a paper appeared in N. Guarino (ed.), Formal Ontology in Information Systems, Proceedings of FOIS'98, Trento, Italy, 6-8 June 1998, Amsterdam, IOS Press, pp. 3-15 URL: http://www.ladseb.pd.cnr.it/infor/Ontology/Papers/FOIS98.pdf

7. Keita A., Laurini R., Roussey C., Zimmerman M.(2004) "Towards an Ontology for Urban Planning: The Towntology Project". In CD-ROM Proceedings of the $24^{\text {th }}$ UDMS Symposium, Chioggia, October 27-29, 2004, pp 12.I.1.

8. Laurini R. (2001) "Information Systems for Urban Planning: A Hypermedia Cooperative Approach", Taylor and Francis, 308 p. February 2001.

9. Roussey C., Laurini R., Beaulieu C., Tardy Y. Zimmermann M. (2004) "Le projet Towntology : Un retour d'expérience pour la construction d'une ontologie urbaine"."Revue Internationale de Géomatique", vol. 14, 2, 2004 pp. 217-237

10. Teller J., Keita A., Roussey C., Laurini R. (2005) "Urban Ontologies for an Improved Communication in Urban Civil Engineering Projects". Int'l Conf. on Spatial Analysis and GEOmatics, (SAGEO 2005), 2005 Avignon, France, June, 20-23, 2005.

11. Toynbee AJ (1970) "Cities on the Move". Oxford University Press. June 1970. 